\title{
Beta blockers exposure and traumatic brain injury: a literature review
}

\author{
Timothy Y. Tran, B.A., Irie E. Dunne, B.A., and John W. German, M.D. \\ Division of Neurosurgery, Department of Surgery Albany Medical College Albany, New York
}

\begin{abstract}
Traumatic brain injury (TBI) continues to carry a significant public health burden and is anticipated to worsen worldwide over the next century. Recently the authors of several articles have suggested that exposure to beta blockers may improve mortality rates following TBI. The exact mechanism through which beta blockers mediate this effect is unknown. In this paper, the authors review the literature regarding the safety of beta blockers in patients with TBI. The findings of several recent retrospective cohort studies are examined and implications for future investigation are discussed. Future questions to be addressed include: the specific indications for the use of beta blockers in patients with TBI, the optimal type and dose of beta blocker given, the end point of beta blocker therapy, and the safety of beta blockers in cases of severe TBIs. (DOI: 10.3171/FOC.2008.25.10.E8)
\end{abstract}

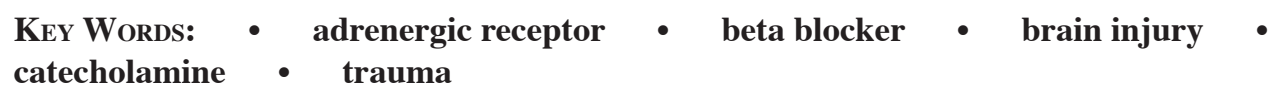

$\mathrm{I}$ $\mathrm{N}$ MODERN, industrialized countries TBI is the leading cause of death and disability in children and young adults, and over the next 2 decades the global public health burden is expected to increase. ${ }^{28,45}$ Although treatment guidelines are now applied effectively to the treatment of these patients, their prognosis remains poor. ${ }^{20}$

A significant proportion of TBIs result in death attributable to nonneurologic organ dysfunction secondary to the initial traumatic insult. ${ }^{23}$ Zygun et al. ${ }^{52}$ observed nonneurologic organ dysfunction in $89 \%$ of patients, with respiratory and cardiovascular failure as the most commonly associated disorders in 23 and 18\%, respectively. Some authors have speculated that the hyperadrenergic state frequently observed after TBI is a prominent contributor to these extracranial injuries. ${ }^{7,8}$ Thus, it may be useful to explore the efficacy of treatments that attenuate the effects of sympathetic hyperactivity, as these may provide survival benefits to patients with TBI.

Recently, the authors of several retrospective studies have sought to determine whether beta blockers can provide a benefit in patients with TBIs. , $^{3,921,38,39}$ In the present study, the rationale and evidence in support of the use of beta blockers in patients with TBI is summarized. We have tried to limit the current discussion to that of the human condition, and invoke animal studies only when

\footnotetext{
Abbreviations used in this paper: AIS = abbreviated injury scale; $\mathrm{BBB}=$ blood-brain barrier; GCS = Glasgow Coma Scale; HRV = heart rate variability; $\mathrm{MABP}=$ mean arterial blood pressure; $\mathrm{OR}=$ odds ratio; $\mathrm{SAH}=$ subarachnoid hemorrhage; $\mathrm{TBI}=$ traumatic brain injury.
}

necessary to provide additional pertinent information for this literature review.

\section{Traumatic Brain Injury and the Catecholamine Surge}

The evidence for a significant catecholamine surge following TBI is summarized in Table 1.7,17,27,49-51 For decades it has been known that brain injury is associated with a significant catecholamine surge. It should be noted that this phenomenon is not unique to TBI and has also been observed after other intracranial processes such as $\mathrm{SAH}^{47}$ and noncerebral insults such as burn injuries. ${ }^{2,19}$ Epinephrine and norepinephrine levels have been observed to increase several fold in patients with TBIs compared with controls. ${ }^{17,27,49-51}$ The initial surge is followed by a hyperadrenergic state lasting a variable time period after the initial trauma. Some authors have noted a correlation between the increase in catecholamine levels, the severity of the TBI, and clinical outcome, ${ }^{7,17,50,51}$ while other investigators have not found such a correlation. ${ }^{27}$ Whether the initial catecholamine surge is detrimental or beneficial to the patient who has sustained a TBI is currently unknown. Certainly from an evolutionary medicine point of view maintenance of cerebral blood flow and metabolism would seem to afford a survival advantage.

Although clinically relevant systemic effects of the catecholamine surge following systemic trauma and traumatic and nontraumatic brain injury have been described in relation to the cardiac, pulmonary, endocrine, and im- 
Table 1: Catecholamine surge after TBI in humans*

\begin{tabular}{|c|c|c|c|c|}
\hline $\begin{array}{l}\text { Authors, } \\
\text { Year }\end{array}$ & $\begin{array}{l}\text { No. of } \\
\text { Patients }\end{array}$ & Normal Levels $†$ & Post-TBI Levels† & Comments \\
\hline $\begin{array}{l}\text { Clifton et } \\
\text { al., } 1981\end{array}$ & 30 & - & - & $\begin{array}{l}\text { plasma NE in TBI patients was negatively correlated } \\
\text { w/ GCS score }(r=-0.49, p<0.001) \text {. }\end{array}$ \\
\hline $\begin{array}{l}\text { Woolf et } \\
\text { al., } 1983\end{array}$ & 17 & $\begin{array}{l}N E=164 \pm 50 ; E=20 \pm \\
6 ; D A=35 \pm 9\end{array}$ & $N E=593 \pm 59 ; E=125 \pm 14 ; D A=34.1 \pm 4.7$ & $\begin{array}{l}\text { plasma NE \& E were significantly elevated compared } \\
w / \text { catecholamine values in healthy volunteers } \\
(p<0.001) \text {. }\end{array}$ \\
\hline $\begin{array}{l}\text { Hamill et } \\
\text { al., } 1987\end{array}$ & 33 & $\begin{array}{l}N E<392 ; E<78 ; D A \\
<105\end{array}$ & $\begin{array}{l}\text { GCS Score } 3-4 \\
\text { NE = } 1686 \pm 416 ; E=430 \pm 172 ; D A=236 \\
\pm 110 \\
\text { GCS Score } 8-11 \\
\text { NE = } 477 \pm 89 ; E=76 \pm 15 ; D A=26 \pm 4\end{array}$ & $\begin{array}{l}\text { NE may have prognostic value: among patients } \\
\text { w/ GCS scores } 3-4 \text {, those who improved to GCS } \\
\text { Score }>11 \text { at } 1 \text { week postinjury had only slightly } \\
\text { elevated NE ( } 544 \pm 89 \text { ); those who died or remained } \\
\text { unchanged had markedly elevated NE (2176 } \pm 531) \text {. }\end{array}$ \\
\hline $\begin{array}{l}\text { Woolf et } \\
\text { al., } 1987\end{array}$ & 61 & $\mathrm{NE}<447 ; \mathrm{E}<71 ; \mathrm{DA}<91$ & $\begin{array}{l}\text { GCS Score } 3-4 \\
N E=1502 \pm 265 ; E=400 \pm 108 ; D A=190 \\
\pm 69 \\
\text { GCS Score } 8-11 \\
N E=413 \pm 47 ; E=102 \pm 14 ; D A=64 \pm 20\end{array}$ & $\begin{array}{l}\text { patients w/ most severe brain injury (GCS Scores } \\
3-4 \text { ) had NE \& E } 4-5 \times \text { normal level; patient NE w/ } \\
\text { GCS scores of 3-4 was predictive of outcome. }\end{array}$ \\
\hline $\begin{array}{l}\text { Woolf et } \\
\text { al., } 1988\end{array}$ & 24 & $\begin{array}{l}\mathrm{NE}=1.79 \pm 0.15 \mathrm{pmol} / \\
\mathrm{ml} ; \mathrm{E}=0.23 \pm 0.04 \mathrm{pmol} / \\
\mathrm{ml} ; \mathrm{DA}=0.90 \pm 0.47 \\
\mathrm{pmol} / \mathrm{ml}\end{array}$ & $\begin{array}{l}\mathrm{NE}=5.80 \pm 1.40 \mathrm{pmol} / \mathrm{ml} ; \mathrm{E}=1.26 \pm 0.32 \\
\mathrm{pmol} / \mathrm{ml} ; \mathrm{DA}=1.04 \pm 0.37 \mathrm{pmol} / \mathrm{ml}\end{array}$ & $\begin{array}{l}\text { GCS score was inversely proportional to degree of } \\
\text { NE \& E increase }(r=-0.41, p<0.0001 \& r=-0.37, p \\
<0.0002)\end{array}$ \\
\hline $\begin{array}{l}\text { Mautes } \\
\text { et al., } \\
2001\end{array}$ & 29 & $\begin{array}{l}\text { plasma NE = 185-275; } \\
\text { CSF NE = 40-120 }\end{array}$ & - & $\begin{array}{l}95 \% \text { of TBI patients w/ NE Tx exhibited elevated } \\
\text { plasma NE } 14 \text { days postinjury, while } 60 \% \text { of patients } \\
\text { w/o Tx had increased plasma NE. }\end{array}$ \\
\hline
\end{tabular}

* $\quad$ CSF = cerebrospinal fluid; $\mathrm{DA}=$ dopamine; $\mathrm{E}=$ epinephrine; $\mathrm{NE}=$ norepinephrine; - = values not provided.

$\dagger$ Catecholamine levels given in $\mathrm{pg} / \mathrm{ml}$ except where otherwise noted.

mune systems, $2,8,12,13,23,25,28,29,35,41,47,48,50,52$ the effects of the catecholamine surge and hyperadrenergic state on the brain are less clear. Adrenergic receptors have been identified in the brain ${ }^{1,22}$ and cerebral vasculature, but there is little clinical evidence of the effects of the catecholamine surge on the brain itself. Bryan ${ }^{6}$ reviewed the effects of stress (but not specifically that of TBI) on cerebral blood flow and energy metabolism. He emphasized the role of beta adrenergic receptors within the brain as a key mediator of stress effects on cerebral blood flow and energy metabolism. He also emphasized that there are 3 main sources of the catecholamines that may stimulate the cerebral beta adrenergic receptors: systemic, from the adrenal medulla; central, from the locus ceruleus; and sympathetic, from the superior cervical ganglia. Whether the survival advantage after TBI incurred by exposure to beta blockers is systemically or centrally mediated is currently unknown. As some beta blockers readily cross the BBB while others do not, the cerebral effects may or may not have clinical implications for future trial design.

\section{Beta Blockers}

Beta blockers were first described and developed in the 1950s. Nobel laureate Sir James W. Black introduced propranolol as the first clinically useful beta blocker for the treatment of angina. Currently, beta blockers are commonly prescribed agents familiar to all physicians with well-known side effect profiles and a proven record of ef- ficacy in the treatment of cardiovascular disease. More recently the clinical indication and application of beta blockers has expanded significantly. 2,19,26,29,46,47 Since the introduction of propranolol, other agents have been developed and several different beta blockers are available clinically. These agents can be classified into 3 generations: 1) first generation or nonselective, 2) second generation or selective, and 3) third generation or specialized. Again we emphasize that some beta blockers readily cross the BBB while others do not, and the cerebral effects may or may not have clinical implications for future trial design.

The possible mechanisms through which beta blockers improve survival remain purely speculative but include systemic, predominantly cardiac, and cerebral effects. Hypothetically, the cardioprotective effects are mediated through a reduction in heart rate, stroke volume, and MABP, which lowers myocardial stroke work, limits myocardial oxygen demand, and thus lowers the risk of myocardial infarction. As cardiac dysfunction is relatively common after $\mathrm{TBI}$, this may represent a significant opportunity through which clinical outcome can be improved. Hypothetically, the neuroprotective effects of beta blockers may be mediated through decreased cerebral blood flow and decreased glucose and oxygen consumption, thus reducing cerebral metabolism.6,35,40 Again this potential benefit remains purely speculative. Finally, a slowing of the catecholamine-induced catabolic state has been demonstrated with the use of beta blockers in 


\section{Beta blocker exposure in TBI}

TABLE 2: Use of beta blockers after TBI in humans*

\begin{tabular}{|c|c|c|c|c|c|c|}
\hline \multirow[b]{2}{*}{ Authors, Year } & \multirow{2}{*}{$\begin{array}{l}\text { Inclusion } \\
\text { Criteria }\end{array}$} & \multicolumn{2}{|c|}{ No. of Patients } & \multicolumn{2}{|c|}{ No. of Patients Who Died (\%) } & \multirow[b]{2}{*}{ p Value } \\
\hline & & $\mathrm{BB}(-)$ & $\mathrm{BB}(+)$ & $\mathrm{BB}(-)$ & $\mathrm{BB}(+)$ & \\
\hline $\begin{array}{l}\text { Arbabi et al., } \\
2007 \dagger\end{array}$ & GCS $<13$ & 511 & 94 & - & - & - \\
\hline $\begin{array}{l}\text { Cotton et al., } \\
2007\end{array}$ & $\begin{array}{l}\text { head AIS } \geq 330< \\
\text { LOS }<4\end{array}$ & 246 & 174 & $27(11)$ & $9(5.2)$ & 0.03 \\
\hline $\begin{array}{l}\text { Riordin et al., } \\
2007\end{array}$ & head AIS $\geq 5$ & 308 & 138 & $135(44)$ & $29(21)$ & $<0.001$ \\
\hline $\begin{array}{l}\text { Salim et al., } \\
2008\end{array}$ & head AIS $\geq 3$ & 329 & 91 & $118(36)$ & $22(24)$ & 0.0363 \\
\hline $\begin{array}{l}\text { Inaba et al., } \\
2008\end{array}$ & $\begin{array}{l}\text { blunt head injury } \\
\text { w/ ICU admis- } \\
\text { sion }\end{array}$ & 953 & 203 & $199(21)$ & $34(17)$ & 0.183 \\
\hline
\end{tabular}

* All evidence in these studies was Level III. BB $(-)=$ not exposed to beta blockers; BB $(+)=$ exposed to beta blockers; ICU = intensive care unit; LOS = length of stay.

† Study includes patients with other traumatic injuries. These numbers reflect only TBIs. Data on TBI mortality rate were not provided.

burn victims. ${ }^{19}$ As hypermetabolism has been associated with brain injury this may represent an additional avenue of efficacy.

Although the specific effects of beta blockers following TBI are currently unknown, there are implications for trial design as both the systemic effects-especially myocardial ischemia and cardiac arrhythmia-and the central effects-especially intracranial pressure and brain oxygenation-must be monitored.

\section{Use of Beta Blockers After TBI}

Because beta blockers have been advocated by the Lund group, we will briefly review their work here., ${ }^{4,11,14-}$ 16,32-35,42,44 Authors of recent retrospective reviews who have suggested a benefit of beta blockers in patients after TBI will then be reviewed. ${ }^{3,9,21,38,39}$ These later studies are summarized in Table 2.

\section{Lund Therapy}

The group from Lund, Sweden, have developed and advocated the use of a management protocol for the treatment of TBI based on volume-targeted therapy principles. The basis for this protocol is the optimization of fluid flow across the BBB to reduce cerebral edema. Measures advocated by the Lund group to achieve this goal include: 1) stress reduction with adequate sedation and catecholamine blockade; 2) maintenance of euvolemia through the use of erythrocyte transfusion and maintenance of a normal albumin level; 3 ) preservation of cerebral perfusion pressure $(60-70 \mathrm{~mm} \mathrm{Hg}$ for adults and 40-55 $\mathrm{mm} \mathrm{Hg}$ for children and adolescents); 4) avoidance of cerebrospinal drainage; 5) use of early nutrition; and 6) use of mechanical ventilation to promote normal oxygenation and ventilation.

In part the protocol advocated by the group from Lund emphasizes the use of metoprolol, a selective beta1antagonist, and clonidine, an alpha2-agonist, which are used to limit the posttraumatic hyperadrenergic stress response. These investigators advocate the use of these agents to limit the formation of cerebral edema. Clonidine mediates systemic vasodilation and inhibits the release of central catecholamine, ${ }^{36}$ and metoprolol reduces myocardial contractility, lowers cardiac output, and lowers MABP. Combined, these drugs can be used to lower MABP, hypothetically reducing capillary hydrostatic pressure to the point where fluid filtration halts and reabsorption can occur. Although this induced reduction in MABP may lower cerebral perfusion pressure, ${ }^{30}$ the Lund group has used hemodynamic ${ }^{4}$ and microdialysis ${ }^{42}$ data to suggest that this effect is well tolerated by patients with brain injuries.

Clinical studies indicate that the volume-targeted Lund therapy may reduce the mortality rate following TBI. To date, several studies have been performed that indicate improved survival in adults ${ }^{11,32,33}$ and children ${ }^{44}$ treated with Lund therapy. Eker and colleagues ${ }^{11}$ conducted a prospective, nonrandomized trial in which 53 patients with severe brain injuries (GCS score $\leq 8$ ) with intracranial hypertension (intracranial pressure $\geq 25 \mathrm{~mm}$ $\mathrm{Hg}$ ) were treated according to the principles of the Lund therapy. Compared with a historical control group, consisting of 38 patients meeting the same selection criteria but treated with conventional principles, mortality was reduced from 47 to $8 \%(\mathrm{p}<0.001)$.

In 2 additional studies in adults with TBI who underwent treatment according to the Lund therapy, Naredi et al. ${ }^{32,33}$ indicate a similar incidence of low mortality and good outcomes. Naredi et al. ${ }^{32}$ reported the results from 38 Lund therapy-treated patients with a $13 \%$ mortality rate. Of the 33 surviving patients, 27 (71\%) were noted to have had a good recovery or moderate disability. In another study, these same authors ${ }^{33}$ report that only 1 of 31 patients who underwent treatment with Lund therapy died, and 22 experienced a good recovery or only moderate disability.

It should be noted that the significance of these re- 
sults is controversial due to the nonrandomized nature of the studies and the use of historical controls. No doubt using a patient group from 1982-1986 as a control for comparison with data obtained in patients over the period 1989-1994 weakens the results of Eker et al..$^{11}$ It has been noted that between those time frames, the general quality of care improved,$^{14}$ and the use of decompressive craniectomies increased. ${ }^{37}$ The lack of a control group in the studies conducted by Naredi et al. ${ }^{32,33}$ compromises their ability to demonstrate that Lund therapy provides a significant survival advantage. Thus, Lund therapy, while promising and apparently based on physiological principles, will require a more comprehensive prospective, randomized clinical trial before the true effects on outcome can be elucidated. Despite these criticisms this group appears to have shown that the adrenergic blocking agents clonidine and metoprolol can be applied to a group of patients with TBI without significant adverse effects.

\section{Retrospective Cohort Studies}

Arbabi and colleagues ${ }^{3}$ published a retrospective cohort study examining the effect of beta blocker exposure on outcome in a group of 4117 trauma patients, of whom 303 received beta blockers. Forty-five percent of the patients taking beta blockers had been prescribed these agents preinjury. These patients were older and had a higher incidence of hypertension, cardiac disease, renal disease, and diabetes. The remainder of the patients exposed to beta blockers received these agents for treatment of blunt aortic injury and for medical complications identified in the course of their hospitalization such as hypertension and tachyarrythmias. This latter group of patients was noted to be more severely injured and have lower GCS scores. After adjusting for confounding factors patients exposed to beta blockers were found to have a lower risk of death. This effect was greatest among patients with clinically significant TBI (GCS score < 13).

Cotton et al. ${ }^{9}$ published a retrospective cohort study that examined the effects of beta blocker exposure in 420 patients with TBI. Inclusion criteria included a length of stay between 4 and 30 days and an AIS score $>3$. The 174 patients exposed to beta blockers, despite being older, more severely injured, having a higher rate of concomitant respiratory and infectious complications, and having a longer average length of stay, demonstrated a mortality rate less than half that of patients who were not exposed to beta blockers (5.1 vs $10.8 \%, \mathrm{p}=0.036$ ). Adjusting for the potential confounders described above, the relative risk of death between the patients exposed to beta blockers and those who were not was 0.29 . With a specific focus on patients with TBI, the study by Cotton et al. also demonstrates a reduction in mortality rates for patients exposed to beta blockers.

Inaba et al. ${ }^{21}$ published a larger retrospective cohort study that also examined the effect of beta blocker exposure on deaths in 1156 patients with TBI. Patients with major associated systemic injuries and those believed to have a nonsurvivable brain injury were excluded. The 203 patients exposed to beta blockers were older, more severely injured, more likely to have sustained a skull fracture, and more likely to undergo a decompressive craniectomy.
After adjusting for confounding factors, the authors reported that exposure to beta blockers was independently associated with a reduction in mortality rates $(\mathrm{OR}=0.54$, $\mathrm{p}<0.01$ ). Following stratification of the patient population by age and injury severity, the authors found that beta blocker exposure provided a significant survival advantage among elderly patients (older than 55 years) with severe head injuries (AIS score $\geq 4$; $O R=0.3, p=0.001$ ), and also among those with severe TBI (GCS score $\leq 8$; $\mathrm{OR}=0.43, \mathrm{p}=0.01$ ). These results suggest that elderly patients with severe TBI could achieve a significant survival advantage with beta blocker treatment.

Although the above studies suggest that exposure to beta blockers may improve survival in patients sustaining a TBI they do not clarify the specific indications for beta blockers in patients with TBI. The authors of 2 other studies have tried to address this issue by evaluating biochemical and physiological data to predict subsets of patients with brian injuries who may benefit most from beta blocker exposure. A specific population that may benefit the most from beta blocker exposure is the subset of patients with brain injuries who exhibit elevated cardiac troponin I levels. Cardiac troponin I has been used as a biochemical marker of myocardial injury, ${ }^{5}$ and elevated cardiac troponin I levels have been observed in acute nontraumatic cerebral insults such as $\mathrm{SAH}$, stroke, and intracerebral hemorrhage,,$^{10,18,31}$ and may reflect a more significant catecholamine surge.

Salim et al. ${ }^{39}$ undertook a retrospective cohort study of 420 patients with TBI, of whom 173 were noted to have elevated cardiac troponin I levels identified either on admission (in 125 patients) or during hospitalization (in 48). Patients who demonstrated elevated cardiac troponin I levels had a lower GCS score, were more severely injured, and had a higher mortality rate. When all the patients were analyzed, those exposed to a beta blocker were significantly less likely to die compared to those who were not ( 24.2 vs $35.9 \%, p=0.0363)$. In the whole group analysis, however, the effect of beta blocker exposure was not shown to independently reduce the mortality rate $(\mathrm{OR}=0.59, \mathrm{p}=0.09)$.

Subgroup analysis confirmed that in patients with an elevated cardiac troponin I level, beta blocker exposure did independently protect against death. Conversely, in patients with a normal cardiac troponin I level, beta blocker exposure did not independently reduce the risk of death. These findings suggest that cardiac troponin I levels may be used as a biochemical marker to predict which patients with TBI will benefit from exposure to beta blockers.

A physiological indicator for beta blockade may be the presence of decreased HRV. The severity of brain injury has been associated with an increase in sympathetic activity and a reduction in parasympathetic tone, an autonomic imbalance that reduces HRV and presumably increases the likelihood of myocardial ischemic injury due to increased metabolic demand..$^{43}$ The administration of propanolol following acute myocardial infarction has been associated with the restoration of parasympathetic tone and diminished sympathetic activity. ${ }^{24}$

Riordin et al. ${ }^{38}$ therefore sought to determine whether 
beta blocker exposure provided a survival advantage in patients with TBI and reduced HRV. The authors examined 446 patients with TBIs with head AIS scores $\geq 5$, of whom 138 received beta blockers. These authors reported that overall patients exposed to beta blockers had a significantly lower mortality rate than those who were not exposed ( $21 \mathrm{vs} 44 \%, \mathrm{p}<0.001)$. Also, while this finding did not reach statistical significance due to inadequate power, there was a notable trend suggesting that beta blocker exposure within the first 24 hours in patients with reduced HRV conveyed a notable reduction in mortality (25 vs $60 \%, \mathrm{p}=0.67)$.

Taken together, these retrospective studies provide consistent evidence to suggest that beta blocker exposure following TBI conveys a survival advantage. A doubleblind, multicenter, prospective randomized trial will be needed to answer this issue definitely. Prior to designing such a trial, several questions must be addressed as outlined below. Some of these questions may be more efficiently addressed through the use of animal models of TBI.

\section{Concluding Thoughts}

Before embarking on such a trial, several basic questions must be answered. Some of these concerns are outlined briefly below:

What are the Best Indications for Beta Blockers in Patients with TBI? As Salim et al. ${ }^{39}$ and Riordin et al. ${ }^{38}$ have suggested, the indications for beta blocker use in patients with TBIs have yet to be defined. Will all such patients benefit from beta blockers, or just a subset of patients?

Which Beta Blocker? Currently, there is no evidence to suggest which beta blocker is the safest or most efficacious to use in patients with TBIs. Although the selective beta blocker metoprolol has been advocated by the Lund group, , $, 11,14-16,32-35,42,44$ a prospective randomized trial published in 1982 suggested a benefit of the nonselective beta blocker propranolol in patients with aneurysmal SAH. ${ }^{47}$ Some beta blockers pass through the BBB and others do not-will this be of clinical importance?

Exposure or Beta Blockade? A central limitation to the studies we have discussed is the lack of knowledge regarding the physiological end point of treatment. While many of the patients may be exposed to beta blockers, it is currently unknown whether the physiological effect of the drug was necessary or even achieved. Whether physiological titration of the chosen beta blocker will be necessary to achieve optimal efficacy is presently unknown.

When Should Beta Blockers Be Started? Based on our current understanding of the effect of hypotension on brain injury, many physicians will have real concerns about potentially exposing a poorly resuscitated patient with brain injuries to the known secondary insult of hypotension. However, Riordin et al. ${ }^{38}$ have suggested that early exposure to beta blockers may be required.

\section{Conclusions}

There is mounting evidence from retrospective cohort studies to suggest that beta blocker exposure in patients who have sustained a TBI limits the mortality rate. Despite these findings, there are multiple unresolved issues that must be addressed prior to embarking on a multicenter, prospective trial of beta blockers in patients with TBI.

\section{Disclosure}

The authors do not report any conflict of interest concerning the materials or methods used in this study or the findings specified in this paper.

\section{References}

1. Alexander RW, Davis JN, Lefkowitz RJ: Direct identification and characterisation of beta-adrenergic receptors in rat brain. Nature 258:437-440, 1975

2. Arbabi S, Ahrns KS, Wahl WL, Hemmila MR, Wang SC, Brandt MM, et al: Beta-blocker use is associated with improved outcomes in adult burn patients. J Trauma 56:265271, 2004

3. Arbabi S, Campion EM, Hemmila MR, Barker M, Dimo M, Ahrns KS, et al: Beta-blocker use is associated with improved outcomes in adult trauma patients. J Trauma 62:56-52, 2007

4. Asgeirsson B, Grände PO, Nordström CH, Berntman L, Messeter K, Ryding E: Effects of hypotensive treatment with alpha 2-agonist and beta 1-antagonist on cerebral haemodynamics in severely head injured patients. Acta Anaesthesiol Scand 39:347-351, 1995

5. Babuin L, Jaffe AS: Troponin: the biomarker of choice for the detection of cardiac injury. CMAJ 173:1191-1202, 2005

6. Bryan RM: Cerebral blood flow and energy metabolism during stress. Am J Physiol 259:H269-H280, 1990

7. Clifton GL, Ziegler MG, Grossman RG: Circulating catecholamines and sympathetic activity after head injury. Neurosurgery 8:10-14, 1981

8. Clifton GL, Robertson CS, Kyper K, Taylor AA, Dhenkne RD, Grossmann RG: Cardiovascular response to severe head injury. J Neurosurg 59:447-454, 1983

9. Cotton BA, Snodgrass KB, Fleming SB, Carpenter RO, Kemp $\mathrm{CD}$, Arbogast PG, et al: Beta-blocker exposure is associated with improved survival after severe traumatic brain injury. J Trauma 62:26-33, 2007

10. Di Angelantonio E, Fiorelli M, Toni D, Sacchetti ML, Lorenzano S, Falcou A, et al: Prognostic significance of admission levels of troponin I in patients with acute ischaemic stroke. J Neurol Neurosurg Psychiatry 76:76-81, 2005

11. Eker C, Asgeirsson B, Grande PO, Schalen W, Nordstrom CH: Improved outcome after severe head injury with a new therapy based on principles for brain volume regulation and preserved microcirculation. Crit Care Med 26:1881-1886, 1998

12. Friese RS, Barber R, McBride D, Bender J, Gentilello LM: Could beta blockade improve outcome after injury by modulating inflammatory profiles? J Trauma 64:1061-1068, 2008

13. Gebhard F, Pfetsch H, Steinbach G, Strecker W, Kinzl L, Bruckner UB: Is interleukin 6 an early marker of injury severity following major trauma in humans? Arch Surg 135:291295, 2000

14. Gisvold SE: The Lund concept for treatment of head injuriesfaith or science? Acta Anaesthesiol Scand 45:399-401, 2001

15. Grande PO: The effects of dihydroergotamine in patients with head injury and raised intracranial pressure. Intensive Care Med 15:523-527, 1989

16. Grande PO, Asgeirsson B, Nordstrom CH: Volume-targeted therapy of increased intracranial pressure: the Lund concept unifies surgical and non-surgical treatments. Acta Anaesthesiol Scand 46:929-941, 2002

17. Hamill RW, Woolf PD, McDonald JV, Lee LA, Kelly M: Catecholamines predict outcome in traumatic brain injury. Ann Neurol 21:438-443, 1987 
18. Hays A, Diringer MN: Elevated troponin levels are associated with higher mortality following intracerebral hemorrhage. Neurology 66:1330-1334, 2006

19. Herndon DN, Hart DW, Wolf SE, Chinkes DL, Wolfe RR: Reversal of catabolism by beta-blockade after severe burns. N Engl J Med 345:1223-1229, 2001

20. Hesdorffer DC, Ghajar J: Marked improvement in adherence to traumatic brain injury guidelines in United States trauma center. J Trauma 63:841-847, 2007

21. Inaba K, Teixeira PG, David JS, Chan LS, Salim A, Brown C, et al: Beta-blockers in isolated blunt head injury. J Am Coll Surg 206:432-438, 2008

22. Joyce JN, Lexow N, Kim SJ, Artymyshym R, Senzon S, Lawrence $\mathrm{D}$, et al: Distribution of beta-adrenergic receptor subtypes in human post-mortem brain: alterations in limbic regions of schizophrenics. Synapse 10:228-246, 1992

23. Kraus J, Conroy C, Cox P, Ramstein K, Fife D: Survival times and case fatality rates of brain-injured persons. J Neurosurg 63:537-543, 1985

24. Lampert R, Ickovics JR, Viscoli CJ, Horwitz RI, Lee FA: Effects of propranolol on recovery of heart rate variability following acute myocardial infarction and relation to outcome in the Beta-Blocker Heart Attack Trial. Am J Cardiol 91:137142,2003

25. Maier B, Lefering R, Lehnert M, Laurer HL, Steudel WI, Neugebauer EA, et al: Early versus late onset of multiple organ failure is associated with differing patterns of plasma cytokine biomarker expression and outcome after severe trauma. Shock 28:668-674, 2007

26. Mangano DT, Layug EL, Wallace A, Tateo I: Effect of atenolol on mortality and cardiovascular morbidity after noncardiac surgery. Multicenter Study of Perioperative Ischemia Research Group. N Engl J Med 335:1713-1720, 1996

27. Mautes AEM, Muller M, Cortbus F, Schwerdtfeger K, Maier $\mathrm{B}$, Holanda M, et al: Alterations of norepinephrine levels in plasma and CSF of patients after traumatic brain injury in relation to disruption of the blood-brain barrier. Acta Neurochir (Wien) 143:51-58, 2001

28. Morganti-Kossmann MC, Satgunaseelan L, Bye N, Kossmann T: Modulation of immune response by head injury. Injury 38:1392-1400, 2007

29. Morel DR, Forster A, Suter PM: Evaluation of I.V. labetalol for treatment of posttraumatic hyperdynamic state. Intensive Care Med 10:133-137, 1984

30. Moss E: Cerebral blood flow during induced hypotension. $\mathbf{B r}$ J Anaesth 74:635-637, 1995

31. Naidech AM, Kreiter KT, Janjua N, Ostapkovich ND, Parra A, Commichau C, et al: Cardiac troponin elevation, cardiovascular morbidity, and outcome after subarachnoid hemorrhage. Circulation 112:2851-2856, 2005

32. Naredi S, Eden E, Zall S, Stephensen H, Rydenhag B: A standardized neurosurgical neurointensive therapy directed toward vasogenic edema after severe traumatic brain injury: clinical results. Intensive Care Med 24:446-451, 1998

33. Naredi S, Olivecrona M, Lindgren C, Ostlund AL, Grande PO, Koskinen LO: An outcome study of severe traumatic head injury using the "Lund therapy" with low-dose prostacyclin. Acta Anaesthesiol Scand 45:402-406, 2001

34. Nilsson F, Nilsson T, Edvinsson L, Bjorkman S, Nordstrom $\mathrm{CH}$ : Effects of dihydroergotamine and sumatriptan on isolated human cerebral and peripheral arteries and veins. Acta Anaesthesiol Scand 41:1257-1262, 1997

35. Nordstrom CH, Messeter K, Sundbarg G, Schalen W, Werner M, Ryding E: Cerebral blood flow, vasoreactivity, and oxygen consumption during barbiturate therapy in severe traumatic brain lesions. J Neurosurg 68:424-431, 1988

36. Payen D, Quintin L, Plaisance P, Chiron B, Lhoste F: Head injury: clonidine decreases plasma catecholamines. Crit Care Med 18:392-395, 1990
37. Polin RS, Shaffrey ME, Bogaev CA, Tisdale N, Germanson T, Bocchicchio B, et al: Decompressive bifrontal craniectomy in the treatment of severe refractory posttraumatic cerebral edema. Neurosurgery 41:84-92, 1997

38. Riordan WP Jr, Cotton BA, Norris PR, Waitman LR, Jenkins JM, Morris JA Jr: Beta-blocker exposure in patients with severe traumatic brain injury (TBI) and cardiac uncoupling. J Trauma 63:503-510, 2007

39. Salim A, Hadjizacharia P, Brown C, Inaba K, Teixeira PG, Chan L, et al: Significance of troponin elevation after severe traumatic brain injury. J Trauma 64:46-52, 2008

40. Schmalbruch IK, Linde R, Paulson OB, Madsen PL: Activation-induced resetting of cerebral metabolism and flow is abolished by beta-adrenergic blockade with propranolol. Stroke 33:251-255, 2002

41. Seekamp A, Jochum M, Ziegler M, van Griensven M, Martin M, Regel G: Cytokines and adhesion molecules in elective and accidental trauma-related ischemia/reperfusion. J Trauma 44:874-882, 1998

42. Stahl N, Ungerstedt U, Nordstrom CH: Brain energy metabolism during controlled reduction of cerebral perfusion pressure in severe head injuries. Intensive Care Med 27:12151223, 2001

43. Su CF, Kuo TB, Kuo JS, Lai HY, Chen HI: Sympathetic and parasympathetic activities evaluated by heart-rate variability in head injury of various severities. Clin Neurophysiol 116:1273-1279, 2005

44. Wahlstrom MR, Olivecrona M, Koskinen LO, Rydenhag B, Naredi S: Severe traumatic brain injury in pediatric patients: treatment and outcome using an intracranial pressure targeted therapy-the Lund concept. Intensive Care Med 31:832-839, 2005

45. World Health Organization, Peden M (ed): World Report on Road Traffic Injury Prevention. Geneva: World Health Organization, 2004 (http://www.paho.org/English/DD/PUB/ Summary_World_report_Road_safety.pdf ) [Accessed 3 September 2008]

46. Wallace A, Layug B, Tateo I, Li J, Hollenberg M, Browner W, et al: Prophylactic atenolol reduces postoperative myocardial ischemia. McSPI Research Group. Anesthesiology 88:7-17, 1998

47. Walter P, Neil-Dwyer G, Cruickshank JM: Beneficial effects of adrenergic blockade in patients with subarachnoid haemorrhage. BMJ 284:1661-1664, 1982

48. Woiciechowsky C, Schoning B, Cobanov J, Lanksch WR, Volk HD, Docke WD: Early IL-6 plasma concentrations correlate with severity of brain injury and pneumonia in braininjured patients. J Trauma 52:339-345, 2002

49. Woolf PD, Akowauah ES, Lee L, Kelly M, Feibel J: Evaluation of the dopamine response to stress in man. J Clin Endocrinol Metab 56:246-250, 1983

50. Woolf PD, Hamill RW, Lee LA, Cox C, McDonald JV: The predictive value of catecholamines in assessing outcome in traumatic brain injury. J Neurosurg 66:875-882, 1987

51. Woolf PD, Hamill RW, Lee LA, McDonald JV: Free and total catecholamines in critical illness. Am J Physiol 254: E87-E291, 1988

52. Zygun DA, Kortbeek JB, Fick GH, Laupland KB, Doig CJ: Non-neurologic organ dysfunction in severe traumatic brain injury. Crit Care Med 33:654-660, 2005

Manuscript submitted June 14, 2008.

Accepted August 28, 2008.

Address correspondence to: John W. German, M.D., Division of Neurosurgery, Department of Surgery, Albany Medical College, 47 New Scotland Avenue, Albany, New York 12108. email: jwgerman@hotmail.com. 